\title{
A Study on the Mechanical Properties and Bursting Liability of Coal-Rock Composites with Seam Partings
}

\author{
Dong Xu $\mathbb{D}^{1,2}$ Mingshi Gao $\mathbb{D}^{1,2}$ Yongliang $\mathrm{He} \mathbb{D}^{1,2}$ and Xin $\mathrm{Yu} \mathbb{D}^{1,2}$ \\ ${ }^{1}$ School of Mines, Key Laboratory of Deep Coal Resource Mining, China University of Mining and Technology, Xuzhou, \\ Jiangsu 221116, China \\ ${ }^{2}$ The State Key Laboratory of Coal Resources and Safe Mining, China University of Mining and Technology, Xuzhou, \\ Jiangsu 221116, China \\ Correspondence should be addressed to Mingshi Gao; cumt_gms@cumt.edu.cn
}

Received 5 March 2021; Revised 1 April 2021; Accepted 10 April 2021; Published 17 April 2021

Academic Editor: Jia Lin

Copyright (c) 2021 Dong Xu et al. This is an open access article distributed under the Creative Commons Attribution License, which permits unrestricted use, distribution, and reproduction in any medium, provided the original work is properly cited.

\begin{abstract}
Geological tectonic movements, as well as complex and varying coal-forming conditions, have led to the formation of rock partings in most coal seams. Consequently, the coal in coal-rock composites is characterised by different mechanical properties than those of pure coal. Uniaxial compression tests were performed in this study to determine the mechanical properties and bursting liability of specimens of coal-rock composites (hereinafter referred to as "composites") with rock partings with different dip angles $\theta$ and thicknesses $D$. The results showed that as $\theta$ increased, the failure mode of the composite changed from tensile and splitting failure to slip and shear failure, which was accompanied by a decrease in the brittleness of the composite and an increase in its ductility as well as a decrease in the extent of fragmentation of the coal in the composite. Additionally, as $\theta$ increased, the uniaxial compressive strength $\sigma_{u}$, elastic modulus $E$, and bursting energy index $K_{e}$ of the composite decreased. The rock parting in the composite was the key area in which elastic energy accumulated. As $D$ increased, $\sigma_{u}, E$, and $K_{e}$ of the composite increased. In addition, as $D$ increased, the ductility of the composite decreased, and the brittleness and extent of coal fragmentation in the composite increased. Notably, the curve for the cumulative acoustic emission (AE) counts of the composite corresponding to the stress-strain curve could be divided into four regimes: pore compaction and closure, a slowly ascending linear elastic section, prepeak steady crack propagation, and peak unsteady crack propagation. The experimental results were used to propose two technologies for controlling the stability of coal-rock composites to effectively ensure safe and efficient production at working faces.
\end{abstract}

\section{Introduction}

Most thick coal seams contain rock partings as a result of complex coal-forming geological conditions $[1,2]$. These partings affect the stability of the working faces and roadway coal ribs in mines and can cause severe rib spalling and support system failure [3-5]. In addition, coal cutters consume more energy during cutting and cutting picks are severely worn down [6-8], significantly affecting the stoping at working faces. Moreover, sparks generated from collisions between cutting picks and rock partings are a major hazard that can trigger gas explosions in gassy coal mines [9]. Rock partings alter the stress distribution in the surrounding rock of coal seams and may produce rock bursts. Stress perturbations induced by mining increase the risks involved in stoping operations at working faces [10]. A coal-rock composite with a seam parting consists of rocks with two lithologies. The anisotropy of the composite increases significantly with the difference between the structural plane and rock mechanical parameters. Interactions between rocks with different lithologies during the failure process produce different mechanical failure characteristics from those of pure coal and pure rock. Thus, it is important to study the mechanical properties and bursting liability of coal-rock composites.

Numerous researchers have extensively studied the mechanical properties of coal-rock composites. Yang et al. [11] studied the mechanical properties and failure modes of 
coal-rock composites for various coal-rock height ratios and determined the corresponding deformation and failure patterns. Gao et al. [12] investigated the brittle failure modes of coal-rock composites under uniaxial compressive loading, analysed energy evolution patterns, and determined the failure mechanisms. Qin et al. [13] studied the energy distribution pattern in each constituent of coal-gritstone-fine sandstone composites before buckling failure and analysed the bursting failure behaviour. Song et al. [14] investigated the failure modes, deformation behaviours, and energy evolution patterns of coal-rock composites under various loading conditions. The study results provided strong support for controlling working faces and the rocks surrounding roadways. Zhang et al. [15] used uniaxial compression tests to investigate the energy evolution patterns and bursting liability of composite specimens with different rock types and produced a reasonable correction to the bursting energy index. Wang et al. [16] studied the progressive failure processes and acoustic emission (AE) characteristics of various coal-rock composites and analysed the bursting liability as well. Xie et al. $[17,18]$ investigated the deformation and failure patterns, as well as the energy evolution mechanisms, of coal-rock composites and proposed stability control principles for composite roofs in deep roadways. Wang et al. [19] used triaxial compression tests to investigate coal-rock composites with various height ratios and determined the stress-strain behaviours. Chen et al. [20] developed mechanical constitutive models for coal and rockcoal-rock composites to analyse the evolutionary patterns of the physical parameters of the rock-coal-rock composites during instability and loading processes. Chen et al. [21] studied the stress-strain behaviour and strength characteristics of composite rock-coal layers. Crack nucleation, propagation, and coalescence patterns in these layers at various loading rates were also investigated. Tan et al. [22] developed a "flexible-hard" combination supporting wall to control the rapid sinking of a hard roof in a roadway. $\mathrm{Lu}$ et al. [23] conducted a series of true triaxial tests on a layered coalrock composite and studied the corresponding deformation and failure laws and mechanical response characteristics. In summary, the aforementioned studies on coal-rock composites have focused primarily on the mechanical properties of coal-rock, rock-coal, or rock-coal-rock composites. By contrast, few studies have been performed on the mechanical properties of coal-rock composites with partings formed from magmatic intrusions into coal seams. Therefore, studying the mechanical properties and bursting liability of coal-rock composites is important for weakening the mechanical properties of rock partings to prevent rock burst and for controlling the stability of rocks surrounding roadways.

In this study, specimens of a coal-rock composite with a rock parting (hereinafter referred to as "composites") with different dip angles $\theta$ and thicknesses $D$ were investigated by uniaxial compressive mechanical testing on an MTS electrohydraulic servo control test machine. The deformation and failure patterns of the composite specimens were recorded using high-speed photography and AE monitoring. The mechanical properties and bursting liability of the composite specimens with different rock-parting characteristics were subsequently analysed. Finally, two technologies for controlling the stability of coal-rock composites were proposed. These technologies can effectively ensure safe and efficient mining at working faces.

\section{Materials and Experimental Methods}

2.1. Material Preparation. Experimental coal-rock samples were collected from the No. 112201 working face of a mine in Shaanxi Province. These rock samples had a sandstone lithology. All the samples were collected from intact and highly homogeneous coal-rock blocks to eliminate interference factors and ensure the reliability of the test results. Cuboidal specimens $(50 \mathrm{~mm} \times 50 \mathrm{~mm} \times 100 \mathrm{~mm})$ were fabricated from the coal-rock samples according to the specifications of the International Society for Rock Mechanics. The ends of each specimen were polished to ensure that the surface roughness of the ends did not exceed $0.2 \mathrm{~mm}$ and the non-parallelism did not exceed $\pm 0.1 \%$. The specimens were divided into groups $\mathrm{A}$ and $\mathrm{B}$. The specimens in group $A$ had $D$ of $20 \mathrm{~mm}$ and $\theta$ values of $10^{\circ}, 20^{\circ}, 30^{\circ}$, and $40^{\circ}$ (three specimens were used for each $\theta$ ). The specimens in group B had $\theta$ of $0^{\circ}$ and $D$ values of 10, 20,30, and $40 \mathrm{~mm}$ (three specimens were used for each $D$ ). An epoxy resin adhesive was used to glue the composite specimens into standard specimens, as shown in Figures 1 and 2.

2.2. Experimental Process. Figure 3 shows the experimental testing system, which consisted primarily of a load control system, an AE monitoring system, and a high-speed digital photographic acquisition system.

An MTS-C64.106 electrohydraulic servo control system was selected as the load control system for the uniaxial compression tests. The strain control mode was used in this study. Each specimen was loaded at a rate of $0.01 \mathrm{~mm} / \mathrm{s}$ until failure.

A PCI-2 AE system was used to monitor the AE activity. Four $\mathrm{AE}$ sensors were adhered to the surfaces of each composite specimen to collect data. The noise suppression threshold, peak definition time, hit lockout time, sampling frequency, and preamplifier gain of the $\mathrm{AE}$ monitoring system were set to $30 \mathrm{~dB}, 50 \mu \mathrm{s}, 300 \mu \mathrm{s}, 2 \mathrm{MHz}$, and $40 \mathrm{~dB}$, respectively. The $\mathrm{AE}$ sensors and each composite specimen were coupled by applying Vaseline.

A GX-1/3 high-speed camera (NAC Inc, Japan) was used to acquire digital photographs to observe the loading process and record the deformation and failure patterns of the composite specimens.

\section{Analysis of the Mechanical Properties of the Composite Specimens}

3.1. Mechanical Properties of the Composite Specimens with Different Dip Angles $(\theta)$. In the composite specimen images, the yellow lines indicate the expansion fractures, and the pink areas indicate the coal body flakes. 


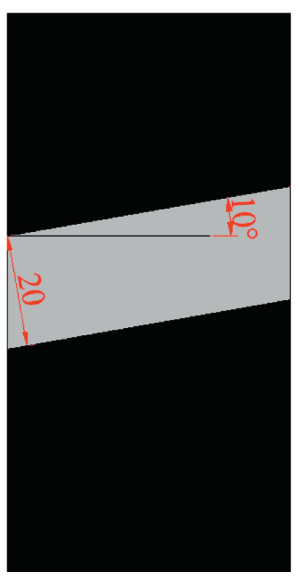

(a)

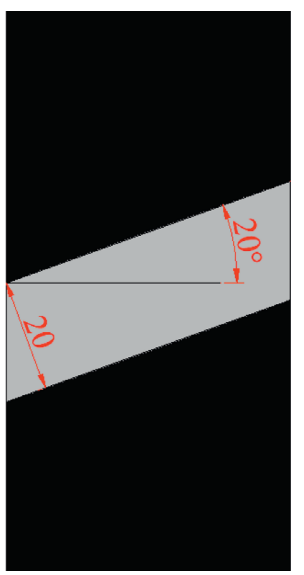

(b)

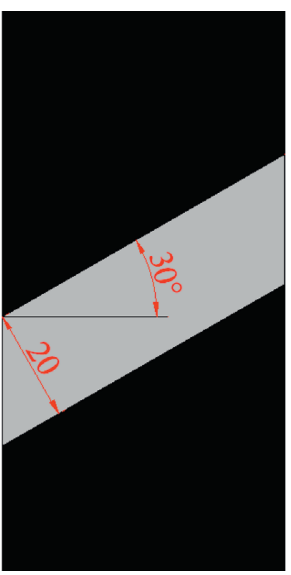

(c)

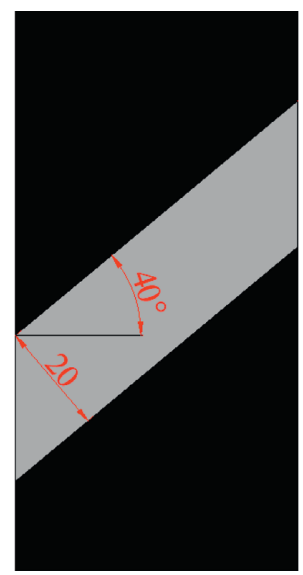

(d)

FIGURE 1: Composite specimens with different rock-parting dip angles $\left(\theta\right.$ ). (a) $10^{\circ}$. (b) $20^{\circ}$. (c) $30^{\circ}$. (d) $40^{\circ}$.

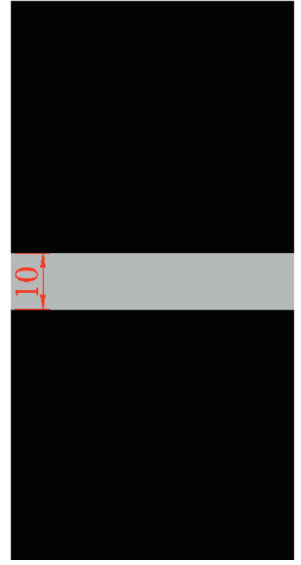

(a)

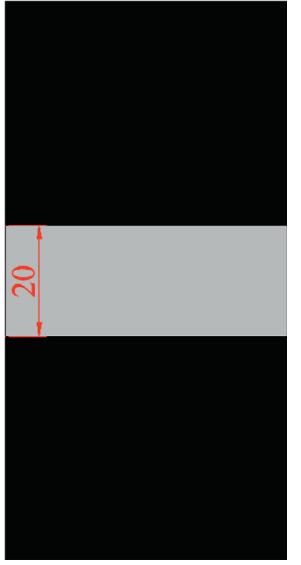

(b)

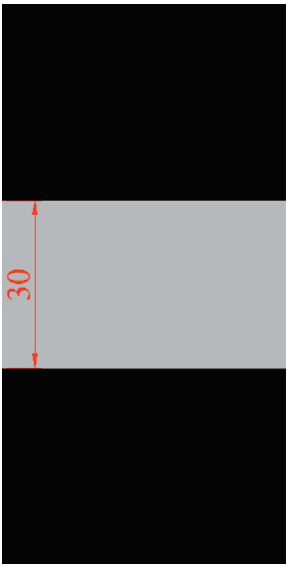

(c)

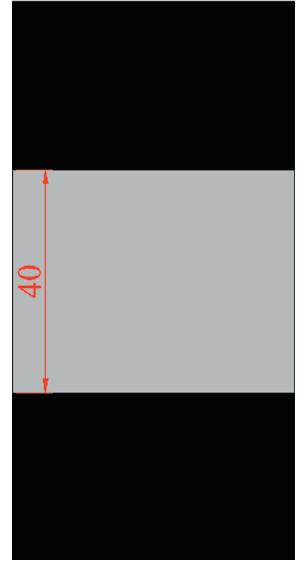

(d)

FIgure 2: Composite specimens with different rock-parting thicknesses (D). (a) $10 \mathrm{~mm}$. (b) $20 \mathrm{~mm}$. (c) $30 \mathrm{~mm}$. (d) $40 \mathrm{~mm}$.

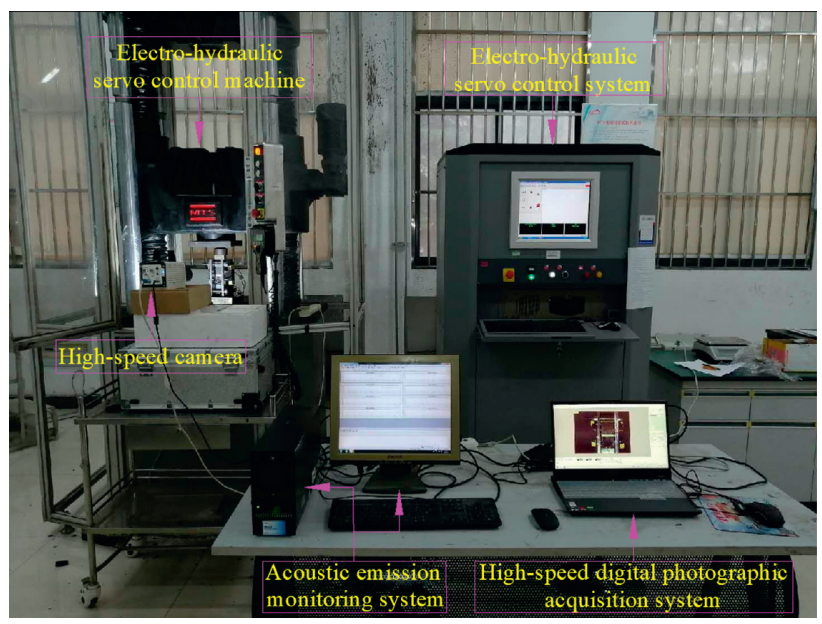

FIGURE 3: The experimental monitoring system. 
The stress-strain curve of the composite could be divided into four regimes: pore compaction (OA), a linear elastic section $(\mathrm{AB})$, prepeak crack development (BC), and postpeak fracture development (CD). During the pore compaction stage, the preexisting cracks and pores in the coal and the rock parting were closed, and the AE activity was weak and fluctuated slightly. The AE activity in the composite remained basically stable over the linear elastic regime. However, there was some propagation of the preexisting cracks in the composite under compressive loading, and a small quantity of coal spalled off in the form of flakes. Consequently, a few AE peaks appeared, albeit with relatively small amplitudes. During prepeak crack development, the cracks inside the composite developed steadily, accompanied by the caving of small coal blocks. A small quantity of rock powder fell off, the coal failed in local areas, there were violent fluctuations in the AE activity, and multiple AE peaks appeared. During postpeak fracture development, small coal blocks erupted accompanied by a notable cracking sound and increasing AE activity. Each steplike sudden increase observed in the cumulative $\mathrm{AE}$ count curve corresponded to the initiation and development of microcracks in the composite, as well as the spalling of coal in the form of flakes. The cumulative AE count curve demonstrably corresponded to the stress-strain curve and could be approximately divided into four regimes: pore compaction and closure (during which the AE count increased slightly); a slowly ascending linear elastic section (during which the AE count increased steadily overall but suddenly increased to a relatively small extent at isolated points as a result of the propagation of the preexisting cracks); prepeak steady crack propagation (during which the propagation of the preexisting cracks intensified, new cracks were initiated, the AE activity increased, and the cumulative AE count curve exhibited a large rate of increase); and peak unsteady crack propagation (during which cracks developed unsteadily, and there was a sharp increase in the cumulative AE count curve).

Increasing $\theta$ shortened the pore compaction regime of the stress-strain curve, changed the failure mode of the composite from tensile failure to slip and shear failure, and decreased the AE activity. Figure 4 shows that at $\theta=10^{\circ}$, horizontally propagating cracks appeared on the surfaces of the lower coal under compressive loading, the lower coal underwent splitting and tensile failure, and the AE count was relatively high. At $\theta=20^{\circ}$, horizontally propagating cracks appeared on the surfaces of the upper coal, and sudden steplike increases occurred in the cumulative $\mathrm{AE}$ count curve. Figure 5 shows that as the loading displacement increased, axial splitting and tensile coalescence appeared in the rock parting and the lower coal during the postpeak fracture development regime of the stress-strain curve. At $\theta=30^{\circ}$, some cracks propagated into the interface between the upper coal and the rock parting, accompanied by a sudden decrease in the stress-strain curve, abnormally high AE counts, and unsteady slip failure of the composite. Figure 6 shows that over the postpeak fracture development regime of the stress-strain curve, the bearing capacity of the composite increased again, the upper coal spalled off in the form of flakes, and there was a gradual increase in the $\mathrm{AE}$ count. At $\theta=40^{\circ}$, the pore compaction regime of the stressstrain curve disappeared, and the linear elastic section was significantly lengthened. There were no notable sudden increases in the AE count during the pore compaction and linear elastic regimes of the stress-strain curve. This result suggests that the increase in $\theta$ prevented notable initiation and propagation of cracks in the composite and that the coal tended to undergo slip failure. AE peaks appeared over the prepeak crack development regime of the stress-strain curve because vertical splitting cracks formed in the upper coal. During the stage postpeak fracture development regime of the stress-strain curve, the interfacial cracks in the composite coalesced, and the upper coal-rock interface underwent steady slip failure, corresponding to a gradual decrease in the $\mathrm{AE}$ count and a slow decrease in the stress-strain curve, as shown in Figure 7.

High-speed photographs of the failure process of the composite showed that the coal failed first in the composite. This is primarily because of the large difference between the strengths of the coal and rock in the composite. The development of internal microcracks resulted in a relatively low coal strength. Consequently, under compressive loading, crack initiation and propagation occurred first in the coal, which spalled off in the form of flakes.

Figure 8 and Table 1 show that as $\theta$ increased, the uniaxial compressive strength $\sigma_{u}$, elastic modulus $E$, and bursting energy index $K_{e}$ of the composite decreased. The $\sigma_{u}$ values of the composite specimens with $\theta$ values of $20^{\circ}, 30^{\circ}$, and $40^{\circ}$ were $16.59 \%, 31.49 \%$, and $57.93 \%$ lower, respectively, than those of the composite specimens with $\theta$ of $10^{\circ}$. The $E$ values of the composite specimens with $\theta$ values of $20^{\circ}$, $30^{\circ}$, and $40^{\circ}$ were $10.64 \%, 16.78 \%$, and $31.08 \%$ lower, respectively, than those of the composite specimen with $\theta$ of $10^{\circ}$. The $K_{e}$ values of the composite specimens with $\theta$ values of $20^{\circ}, 30^{\circ}$, and $40^{\circ}$ were $13.98 \%, 30.02 \%$, and $37.63 \%$ lower, respectively, than those of the composite specimens with $\theta$ of $10^{\circ}$. This is mainly because as $\theta$ increased, the failure mode of the composite changed from splitting and tensile failure to slip and shear failure. Consequently, the composite was more prone to slip and shear failure along the coal-rock interfaces under uniaxial compressive loading. Thus, the composite $\sigma_{u}$ decreased as $\theta$ increased. The preferential failure of the composite along the weak structural planes hindered the accumulation of elastic energy, resulting in a notable decrease in $K_{e}$. The composite became less fragmented and remained more intact as $\theta$ increased.

\subsection{Mechanical Properties of Composite Specimens with} Different Thicknesses (D). Similarly, the stress-strain curve of each of the composite specimens with different $D$ values could be divided into four characteristic regimes of failure development. There was a notable correspondence between the stress-strain and cumulative AE count curves. Increasing $D$ caused an increase in the ductility and a decrease in the brittleness of the composite.

For the composite specimen with $D=10 \mathrm{~mm}$ under uniaxial compressive loading, crack propagation occurred in 


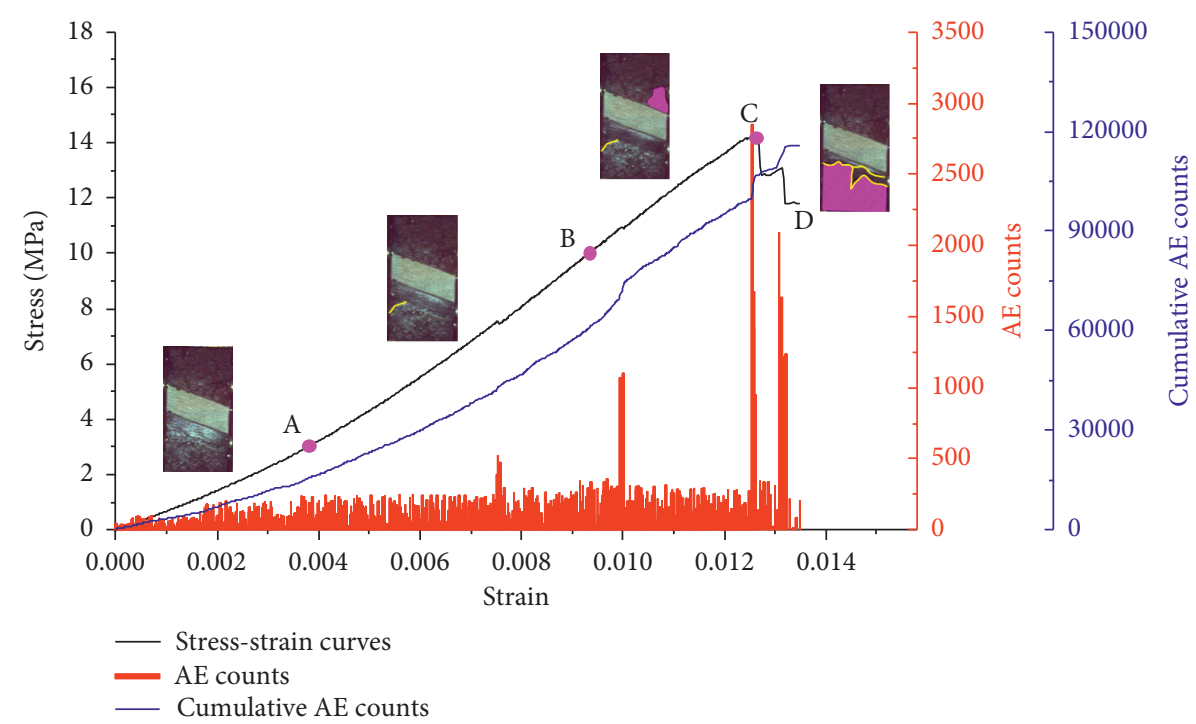

FIGURE 4: Stress-strain curve and acoustic emission monitoring curve of composite specimens with a $10^{\circ}$ dip angle (A10-1).

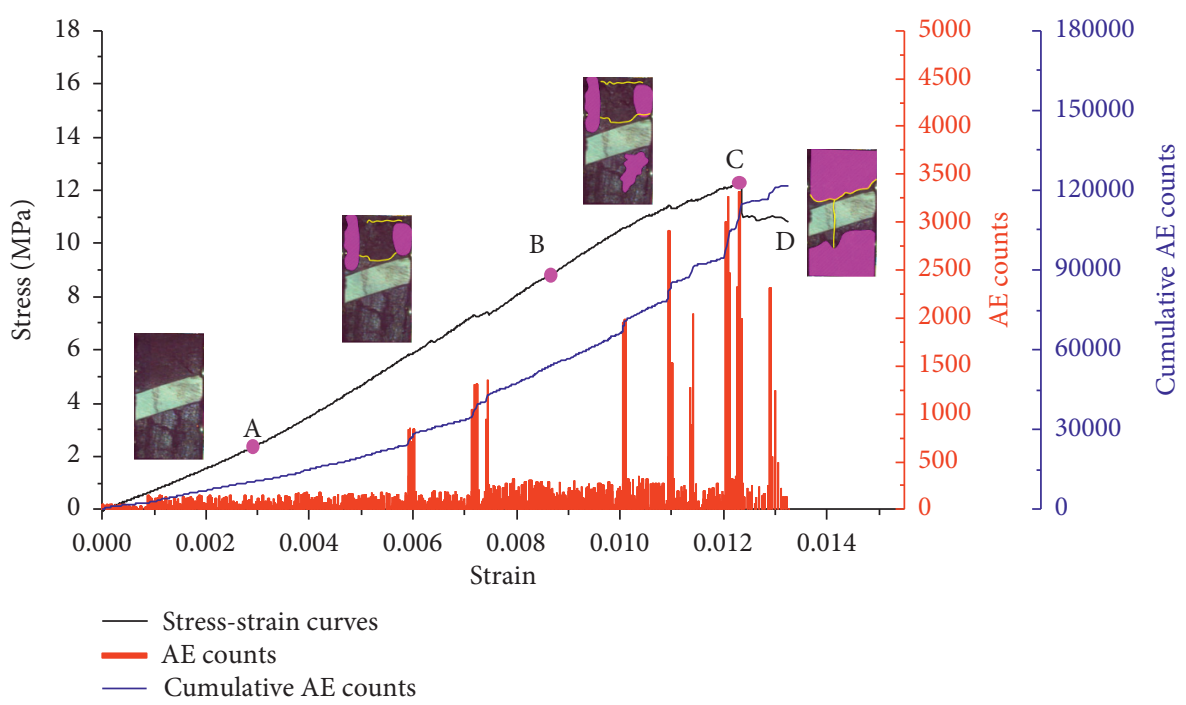

FIGURE 5: Stress-strain curve and acoustic emission monitoring curve of composite specimens with a 20 dip angle (A20-1).

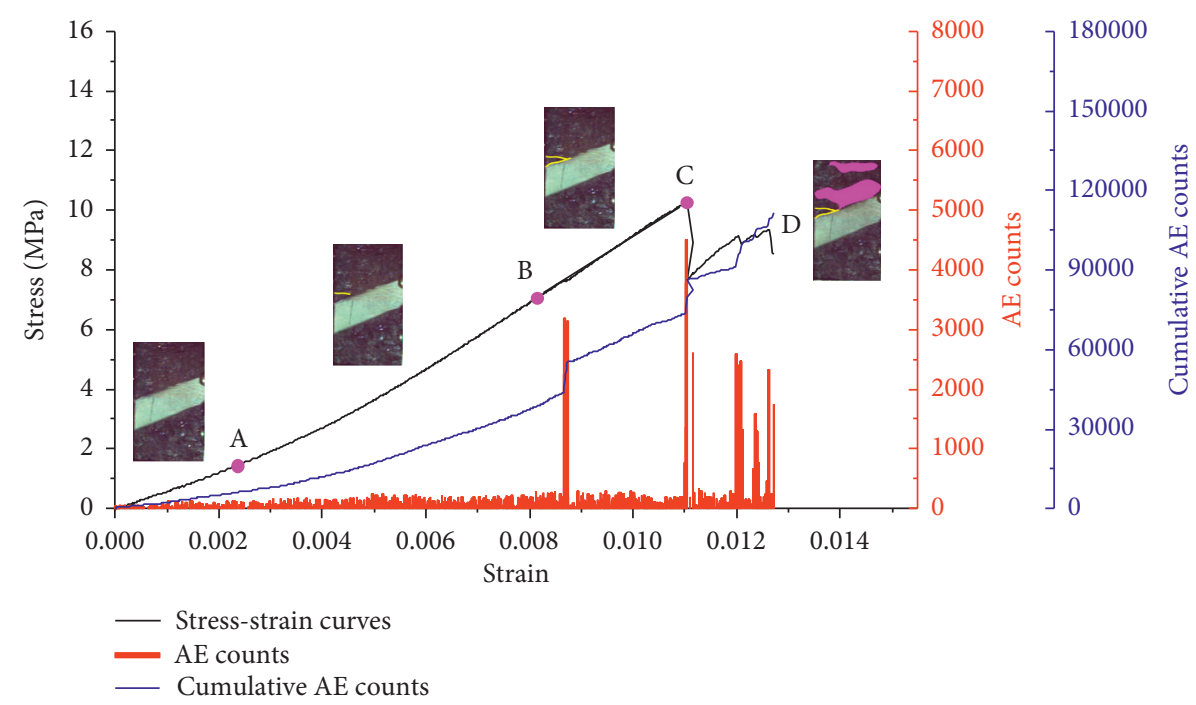

FIgURE 6: Stress-strain curve and acoustic emission monitoring curve of composite specimens with a $30^{\circ}$ dip angle (A30-1). 


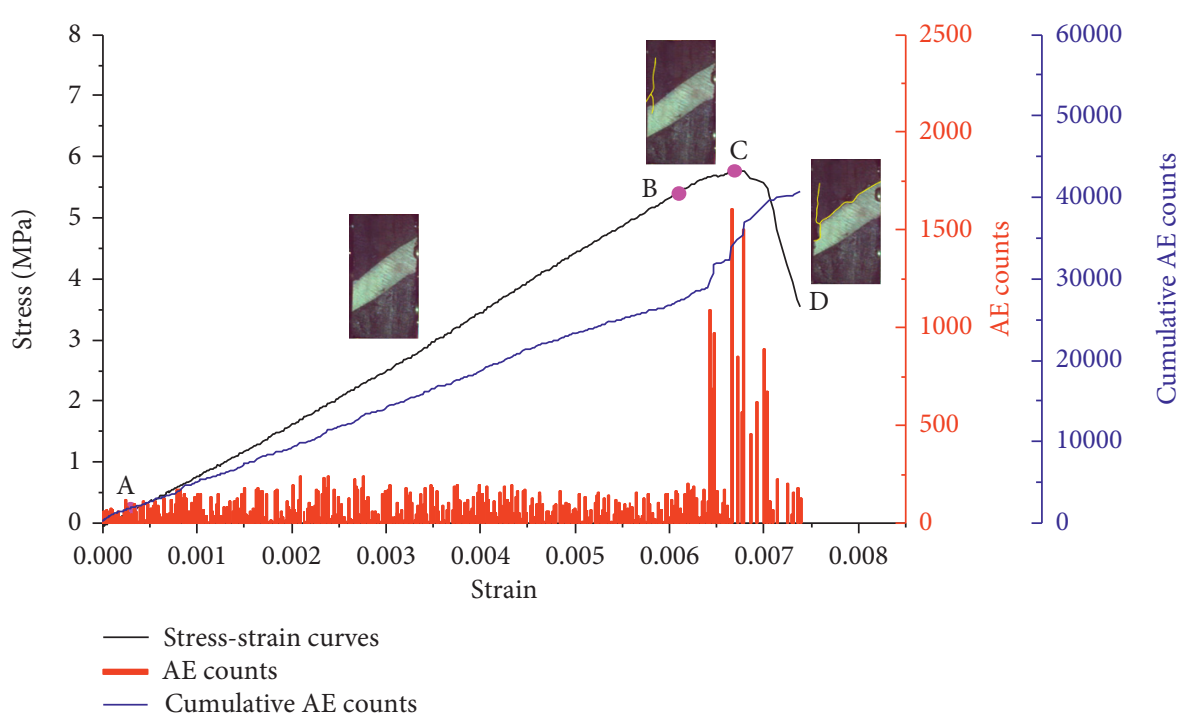

FIgURE 7: Stress-strain curve and acoustic emission monitoring curve of composite specimens with a $40^{\circ}$ dip angle (A40-1).

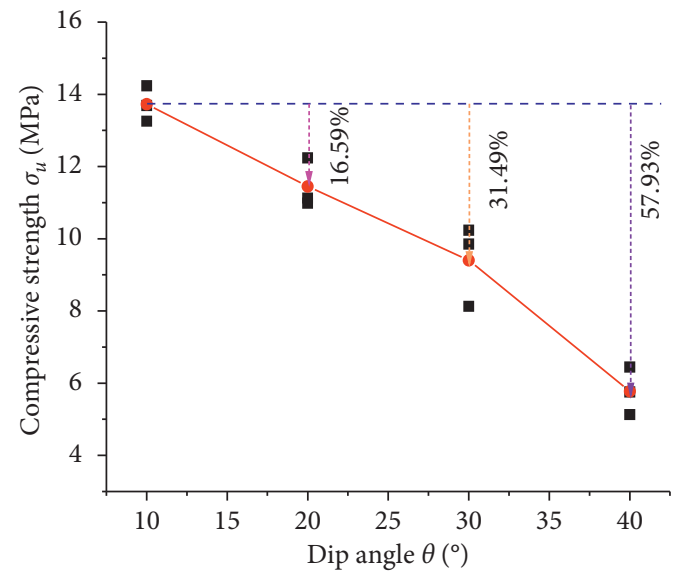

- Test value

- - Average value

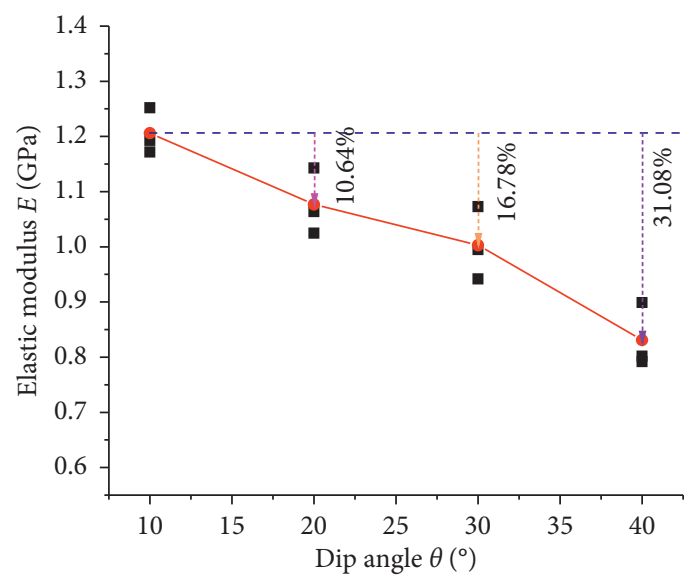

- Test value

- - Average value

(b)

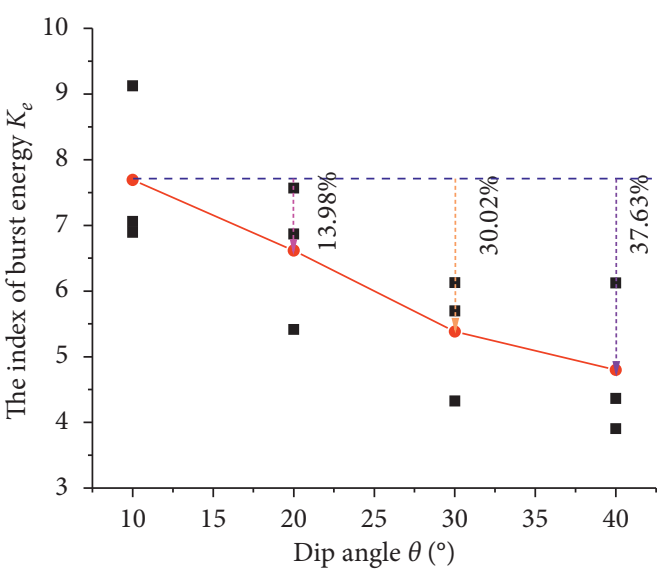

- Test value

$-\bullet$ Average value

(c)

FIGURE 8: Test results of the mechanical parameters of composite specimens with different dip angles. (a) Uniaxial compressive strength. (b) Elastic modulus. (c) Bursting energy index. 
TABle 1: Mechanical parameters of composite specimens with different dip angles.

\begin{tabular}{|c|c|c|c|c|c|c|}
\hline \multirow[b]{2}{*}{ Specimen group } & \multicolumn{2}{|c|}{$\begin{array}{c}\text { Uniaxial compressive } \\
\text { strength } \sigma_{u}(\mathrm{MPa})\end{array}$} & \multicolumn{2}{|c|}{ Elastic modulus E (GPa) } & \multicolumn{2}{|c|}{ Bursting energy index $K_{e}$} \\
\hline & Tested & Average & Tested & Average & Tested & Average \\
\hline A10-1 & 14.236 & \multirow{3}{*}{13.726} & 1.172 & \multirow{3}{*}{1.206} & 7.059 & \multirow{3}{*}{7.694} \\
\hline A $10-2$ & 13.254 & & 1.252 & & 6.896 & \\
\hline A $10-3$ & 13.689 & & 1.193 & & 9.126 & \\
\hline A20-1 & 12.240 & \multirow{3}{*}{11.449} & 1.064 & \multirow{3}{*}{1.077} & 6.870 & \multirow{3}{*}{6.618} \\
\hline A20-2 & 11.123 & & 1.143 & & 7.569 & \\
\hline A20-3 & 10.985 & & 1.025 & & 5.415 & \\
\hline A30-1 & 10.234 & \multirow{3}{*}{9.404} & 0.942 & \multirow{3}{*}{1.003} & 4.325 & \multirow{3}{*}{5.384} \\
\hline A30-2 & 9.853 & & 1.073 & & 5.698 & \\
\hline A30-3 & 8.126 & & 0.995 & & 6.129 & \\
\hline $\bar{A} 40-1$ & 5.756 & \multirow{3}{*}{5.775} & 0.899 & \multirow{3}{*}{0.831} & 6.125 & \multirow{3}{*}{4.799} \\
\hline $\mathrm{A} 40-2$ & 6.443 & & 0.792 & & 4.365 & \\
\hline $\mathrm{A} 40-3$ & 5.125 & & 0.802 & & 3.906 & \\
\hline
\end{tabular}

the lower coal, which underwent splitting and tensile failure. The rock parting had an insignificant impact on the strength and failure of the composite, where the strength was dictated primarily by the coal strength, as shown in Figure 9. The composite specimen with $D=20 \mathrm{~mm}$ was comparatively more anisotropic, and the rock parting accumulated more energy. As considerable space was vacated by crack propagation in the coal, the sudden release of the elastic energy accumulated in the rock parting at the coal-rock interfaces resulted in the violent failure of the composite and abnormally high AE counts, as shown in Figure 10. Crack propagation occurred in the upper and lower coal of composite specimen $\mathrm{B} 30-1 \quad(D=30 \mathrm{~mm})$, accompanied by stretching and spalling, an increase in displacement, and the sudden release of the elastic energy accumulated in the rock parting, resulting in the bursting failure of the specimen, as shown in Figure 11(a). In composite specimen B30-2 $(D=30 \mathrm{~mm})$, the initiation of cracks in the rock parting did not provide conditions for the sudden release of accumulated elastic energy. Thus, the rock parting underwent static splitting and tensile coalescence failure, as shown in Figure 11(b). The composite specimen with $D=40 \mathrm{~mm}$ underwent bursting failure, with notable crack propagation in the rock parting, primarily because more energy had accumulated than for the rock parting with $D=30 \mathrm{~mm}$. The considerable strain in the coal caused the rock parting to rebound and suddenly release the accumulated elastic energy, causing violent failure of the composite, as shown in Figure 12. The initiation and propagation of cracks in the composite corresponded to decreases in stress (as evidenced by the stress-strain curves) and sudden increases in the cumulative AE count (as shown by the cumulative AE count curves). Thus, the AE counts effectively reflected the internal crack propagation patterns in the composites.

Figure 13 and Table 2 show that as $D$ increased, $\sigma_{u}, E$, and $K_{e}$ of the composite increased. The $\sigma_{u}$ values of the composite specimens with $D$ values of 20,30 , and $40 \mathrm{~mm}$ were $13.58 \%, 24.62 \%$, and $57.21 \%$ higher, respectively, than those of the composite specimens with $D$ of $10 \mathrm{~mm}$. The $E$ values of the composite specimens with $D$ values of 20,30 , and $40 \mathrm{~mm}$ in $D$ were $10.55 \%, 23.06 \%$, and $41.31 \%$ higher, respectively, than those of the composite specimens with $D$ of $10 \mathrm{~mm}$. The $K_{e}$ values of the composite specimens with $D$ values of 20,30 , and $40 \mathrm{~mm}$ were $174.57 \%, 194.97 \%$, and $361.68 \%$ higher, respectively, than those of the composite specimens with $D$ of $10 \mathrm{~mm}$.

As $D$ increased, the rock parting became the main loadbearing structure, and $\sigma_{u}$ and $K_{e}$ of the composite increased, as did the risk of bursting. Under uniaxial compressive loading, the rock parting was the key structure for accumulating energy due to its relatively high strength. The relatively low coal strength enabled micro- and macrocracks to develop in the coal before the ultimate failure strength of the rock parting was reached, causing a relatively large displacement in the coal and generating a relatively large vacated space. Under these conditions, the rock parting rebounded and released the accumulated elastic energy, which precipitated the violent bursting failure of the coal. Rebounding generated a tensile stress in the rock parting and caused similar splitting and tensile failure of the surfaces. However, premature crack propagation divested the rock parting of the preconditions for accumulating energy. The corresponding composite specimens in this study were found to exhibit static failure characteristics with a considerably lower risk of bursting. The larger the composite $D$ was, the higher the capacity of the rock parting to accumulate elastic energy was. The release of elastic energy from the rock parting increased the extent of fragmentation of the coal. The larger $D$ was, the more fragmented the coal was.

\section{Engineering Applications}

The experimental results were used to formulate two technologies for controlling the stability of the surrounding rock (Figure 14). (1) Excavation causes the surrounding rock stress at the free face of a roadway to transition from a three-dimensional stress state to a two-dimensional or unidirectional stress state, thereby decreasing the rock stability. The presence of partings increases the strength anisotropy of the coal-rock composite surrounding the roadway. Under the mining-induced surrounding rock stress, the coal ribs of a roadway significantly spall off. 


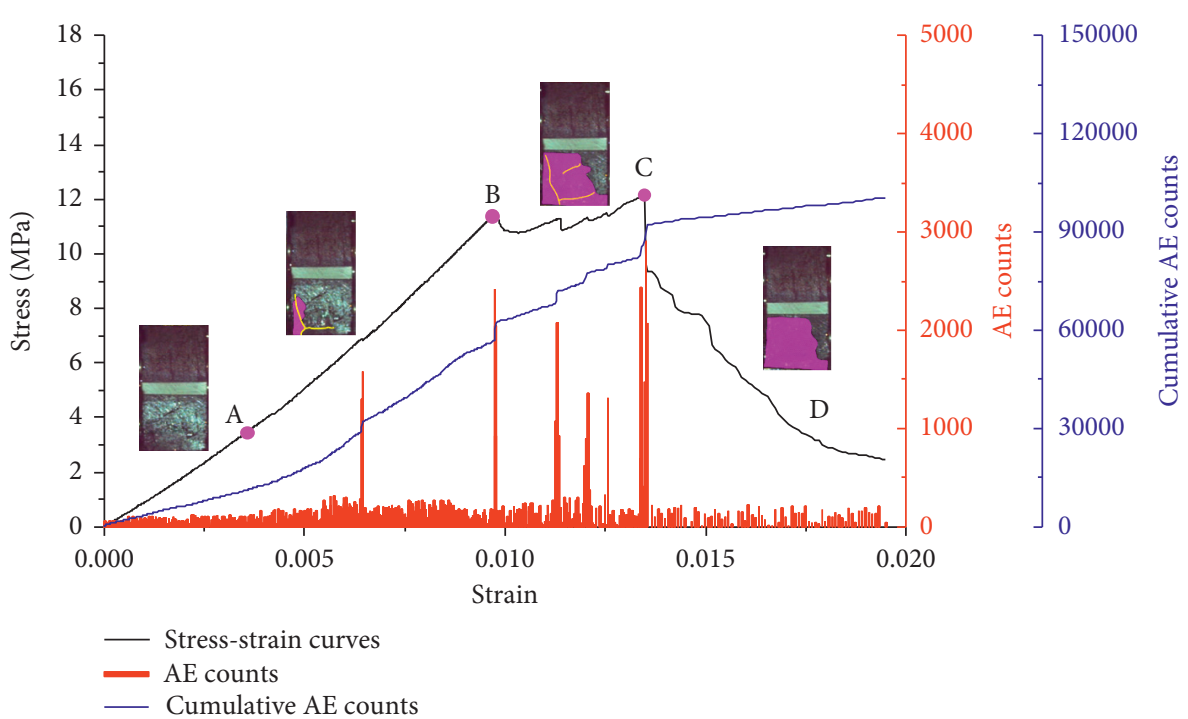

FIGURE 9: Stress-strain curve and acoustic emission monitoring curve of $10 \mathrm{~mm}$-thick composite specimens (B10-1).

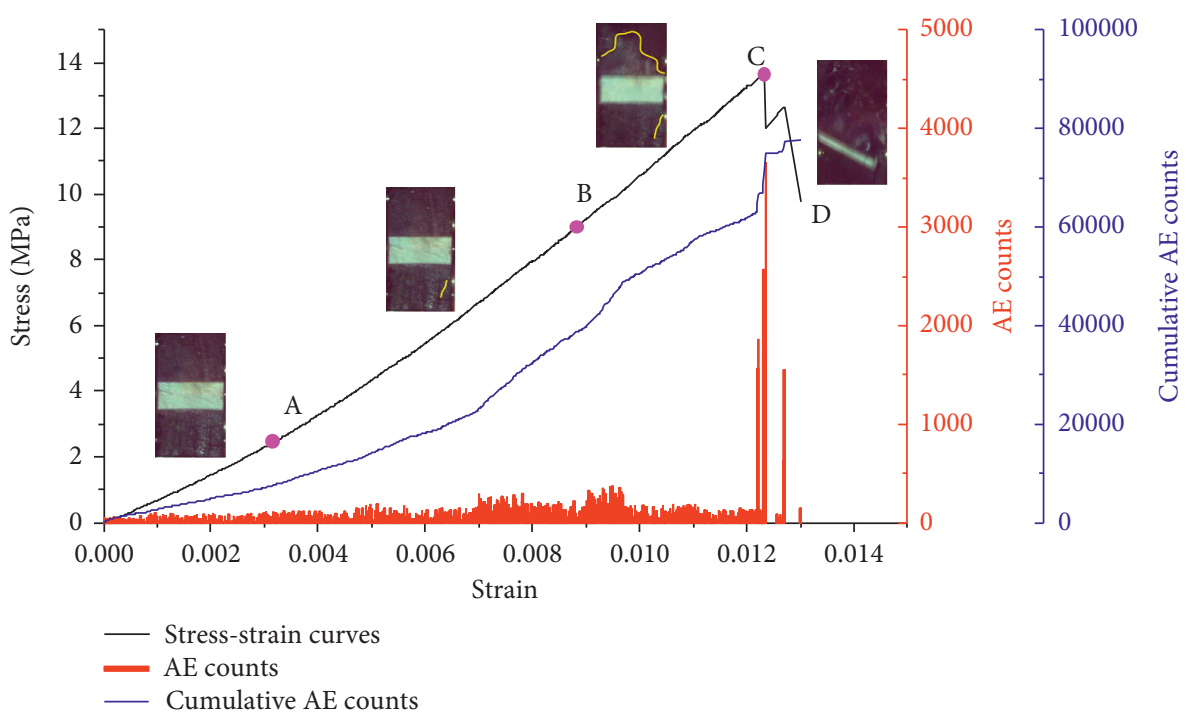

FiguRE 10: Stress-strain curve and acoustic emission monitoring curve of $20 \mathrm{~mm}$-thick composite specimens (B20-1).

Consequently, an asymmetric strengthening support technology can be used to increase the strength of coal-seam support systems, reduce the difference between the strengths of the coal and rock in coal-rock composites, and maintain the stability of roadway surrounding rocks. (2) Under uniaxial compression, the initiation and propagation of microjoints and microcracks damages the coal in a coal-rock composite and thereby releases part of the accumulated elastic energy in the rock. Thus, the extent of damage sustained by the coal increases, and bursting is induced. It is necessary to reduce the extent of damage sustained by coalrock composites, the bursting risk, and the coal cutting energy consumption. These goals can be achieved by using high-pressure fracturing to weaken and disrupt the integrity of rock partings, reduce the strength anisotropy of coal-rock composites, and decrease the risk of bursting in coal seams.
Mining is currently underway in the No. 2 coal seam of a mine in the Yushen mining area in Shaanxi. This coal seam, with an average burial depth of $370 \mathrm{~m}$, is at low risk of rock burst. The No. 112201 working face of this coal seam, $350 \mathrm{~m}$ in length and $4,556.6 \mathrm{~m}$ in strike length, contains one to two partings overall but three partings in some local areas. The parting thickness is $0.6-2.0 \mathrm{~m}$. The high hardness coefficient of the partings hinders excavation and makes cutting difficult. In addition, coal blocks are ejected during the cutting process, and the rocks surrounding the roadway have low stability and significantly spall off. To reduce the energy consumption of coal cutters and the dynamic manifestation at the working face, high-pressure pulsed water-jet fracturing technology was employed to reduce the strength of the partings at the working face. Figure 15 shows the partings at the working face before and after weakening. 

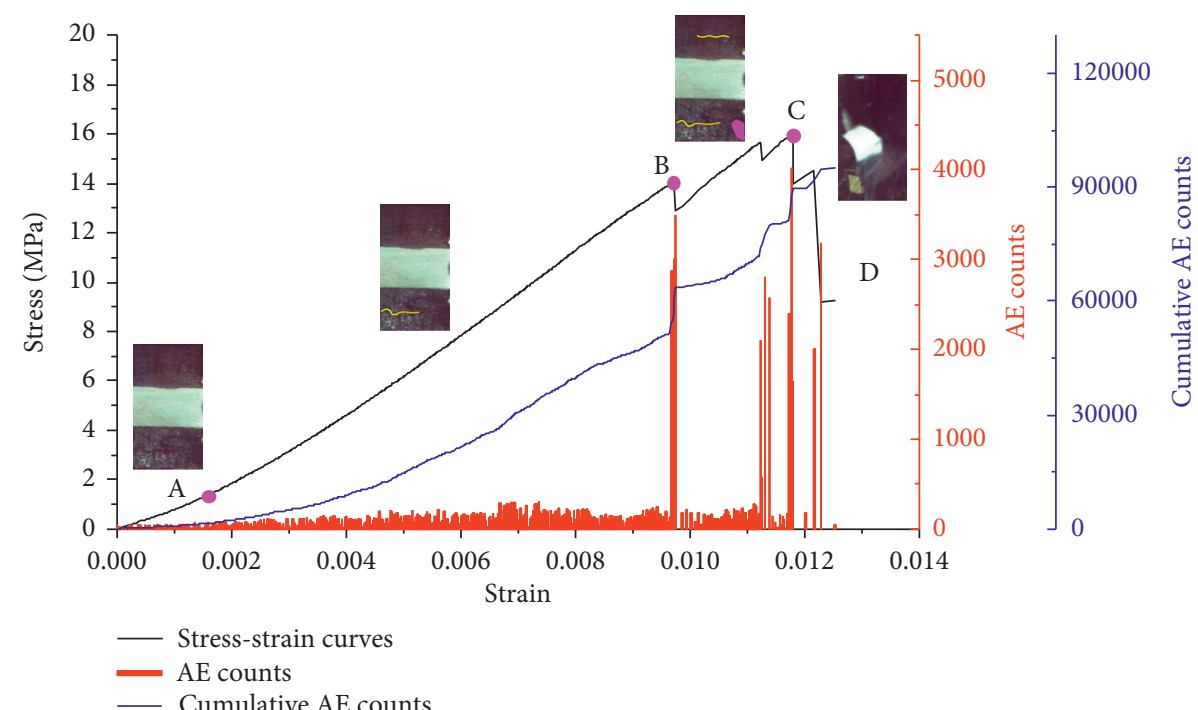

(a)

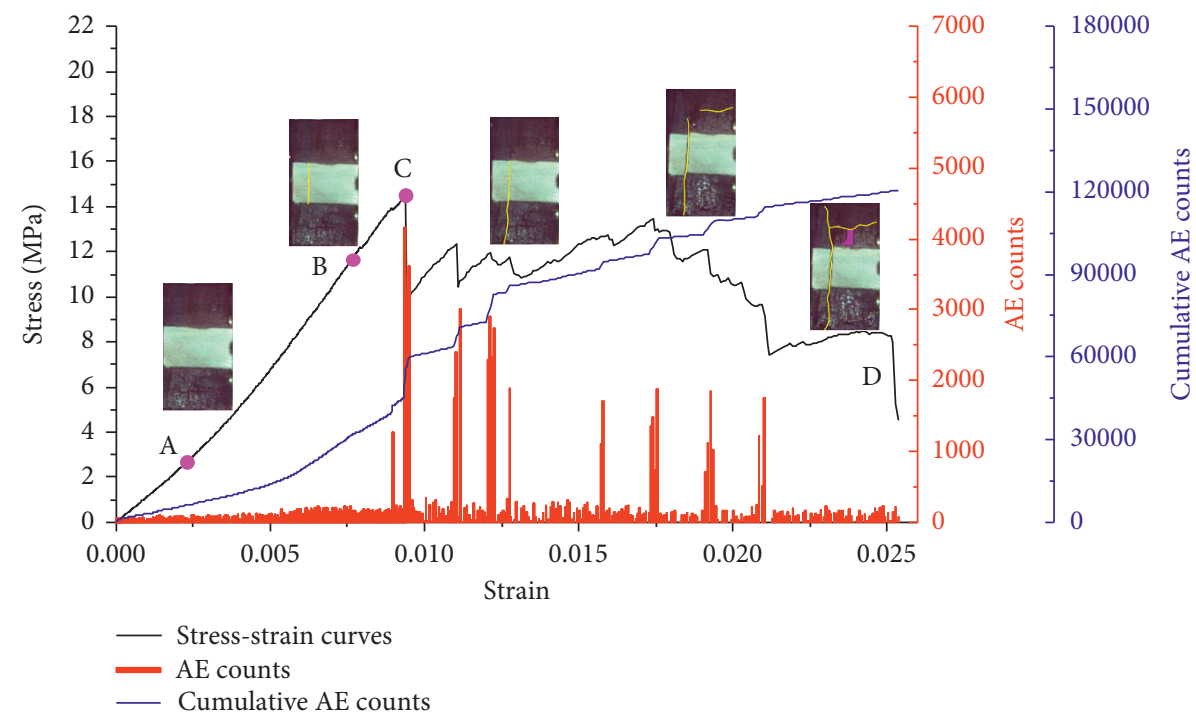

(b)

FigURE 11: Stress-strain curve and acoustic emission monitoring curve of $30 \mathrm{~mm}$-thick composite specimens. (a) B30-1. (b) B30-2.

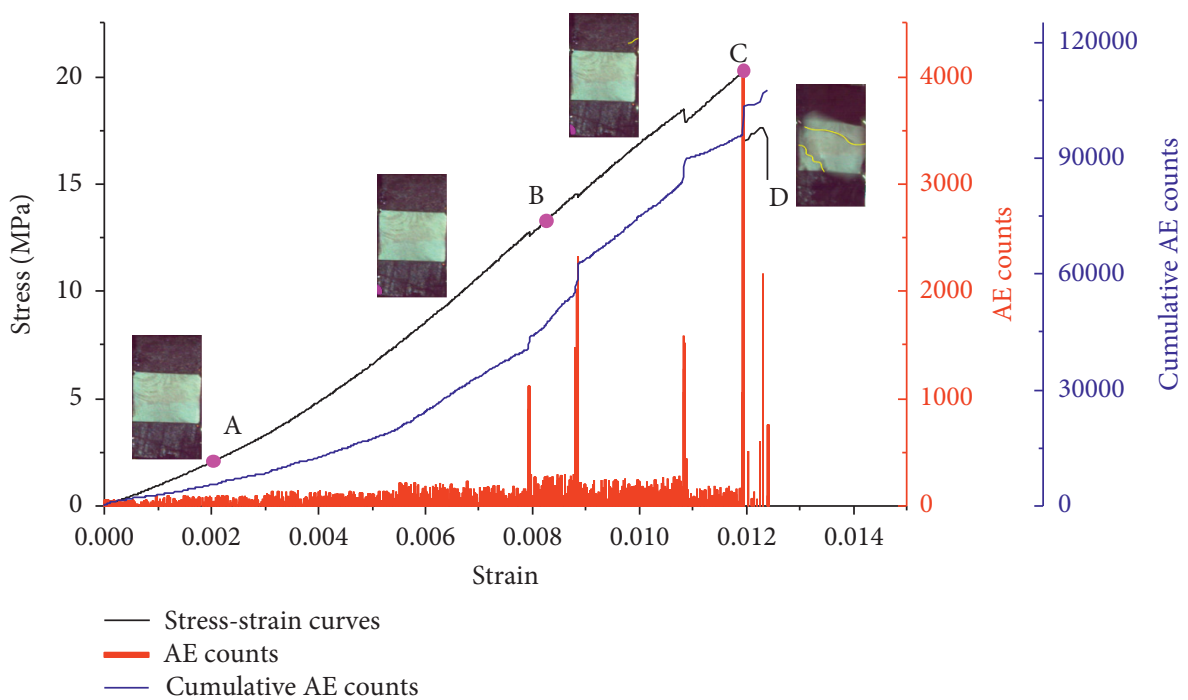

FIgURE 12: Stress-strain curve and acoustic emission monitoring curve of $40 \mathrm{~mm}$-thick composite specimens. 


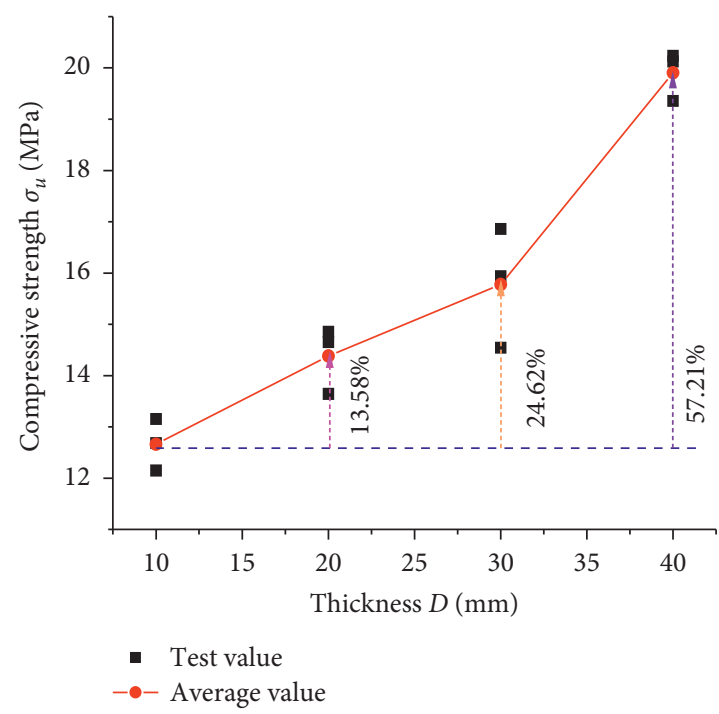

(a)

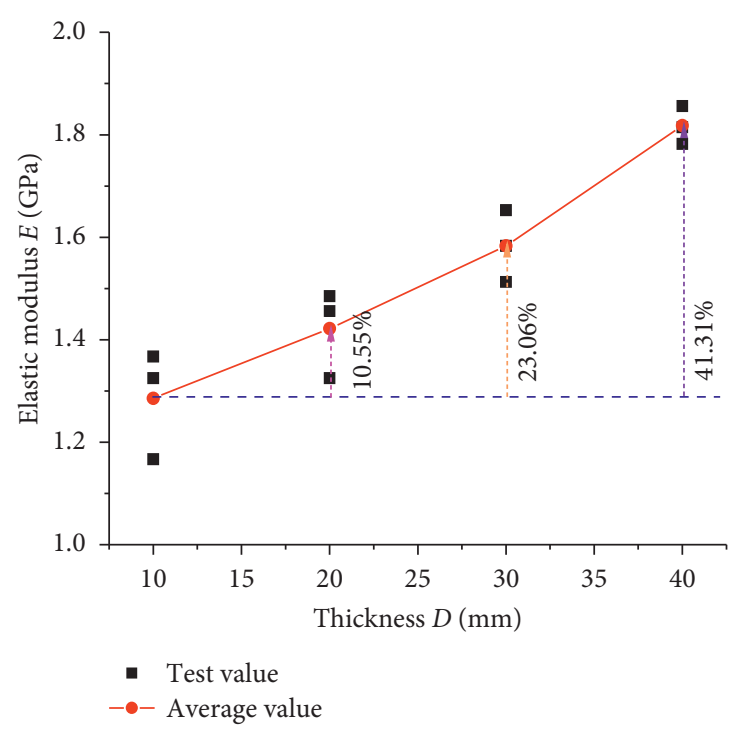

(b)

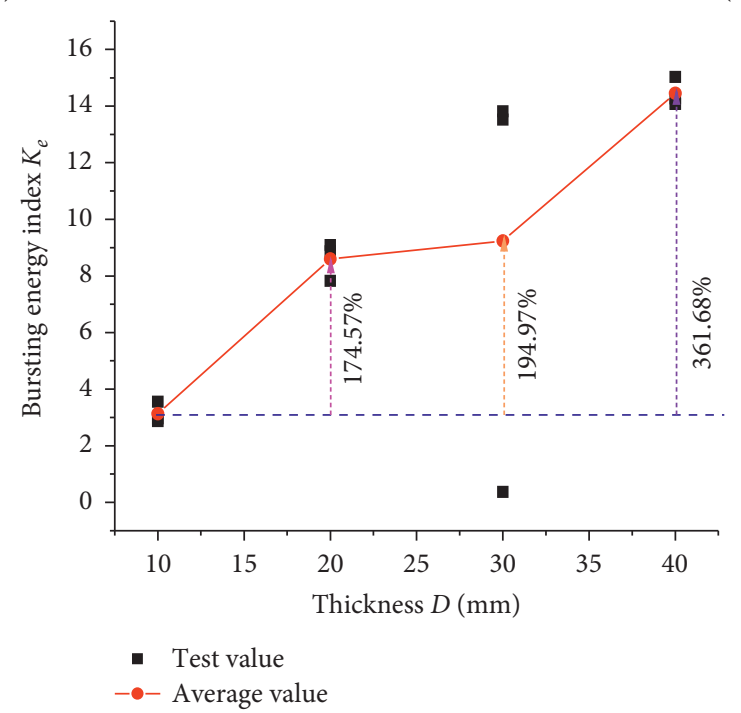

(c)

FIGURE 13: Test results of the mechanical parameters of composite specimens with different thicknesses. (a) Uniaxial compressive strength. (b) Elastic modulus. (c) Bursting energy index.

TABLe 2: Mechanical parameters of composite specimens with different thicknesses.

\begin{tabular}{|c|c|c|c|c|c|c|}
\hline \multirow[b]{2}{*}{ Specimen group } & \multicolumn{2}{|c|}{$\begin{array}{l}\text { Uniaxial compressive } \\
\text { strength } \sigma_{u}(\mathrm{MPa})\end{array}$} & \multicolumn{2}{|c|}{ Elastic modulus E (GPa) } & \multicolumn{2}{|c|}{ Bursting energy index $K_{e}$} \\
\hline & Tested & Average & Tested & Average & Tested & Average \\
\hline B10-1 & 12.148 & \multirow{3}{*}{12.662} & 1.167 & \multirow{3}{*}{1.286} & 2.968 & \multirow{3}{*}{3.131} \\
\hline $\mathrm{B} 10-2$ & 12.685 & & 1.325 & & 3.556 & \\
\hline $\mathrm{B} 10-3$ & 13.154 & & 1.367 & & 2.869 & \\
\hline B20-1 & 13.644 & \multirow{3}{*}{14.382} & 1.325 & \multirow{3}{*}{1.422} & 9.091 & \multirow{3}{*}{8.597} \\
\hline $\mathrm{B} 20-2$ & 14.851 & & 1.485 & & 8.873 & \\
\hline B20-3 & 14.652 & & 1.456 & & 7.826 & \\
\hline B30-1 & 15.936 & \multirow{3}{*}{15.779} & 1.513 & \multirow{3}{*}{1.583} & 13.521 & \multirow{3}{*}{9.236} \\
\hline B30-2 & 14.543 & & 1.583 & & 0.371 & \\
\hline $\mathrm{B} 30-3$ & 16.859 & & 1.653 & & 13.815 & \\
\hline B40-1 & 20.237 & \multirow{3}{*}{19.906} & 1.782 & \multirow{3}{*}{1.818} & 14.071 & \multirow{3}{*}{14.455} \\
\hline B40-2 & 20.125 & & 1.856 & & 15.026 & \\
\hline B $40-3$ & 19.356 & & 1.815 & & 14.269 & \\
\hline
\end{tabular}




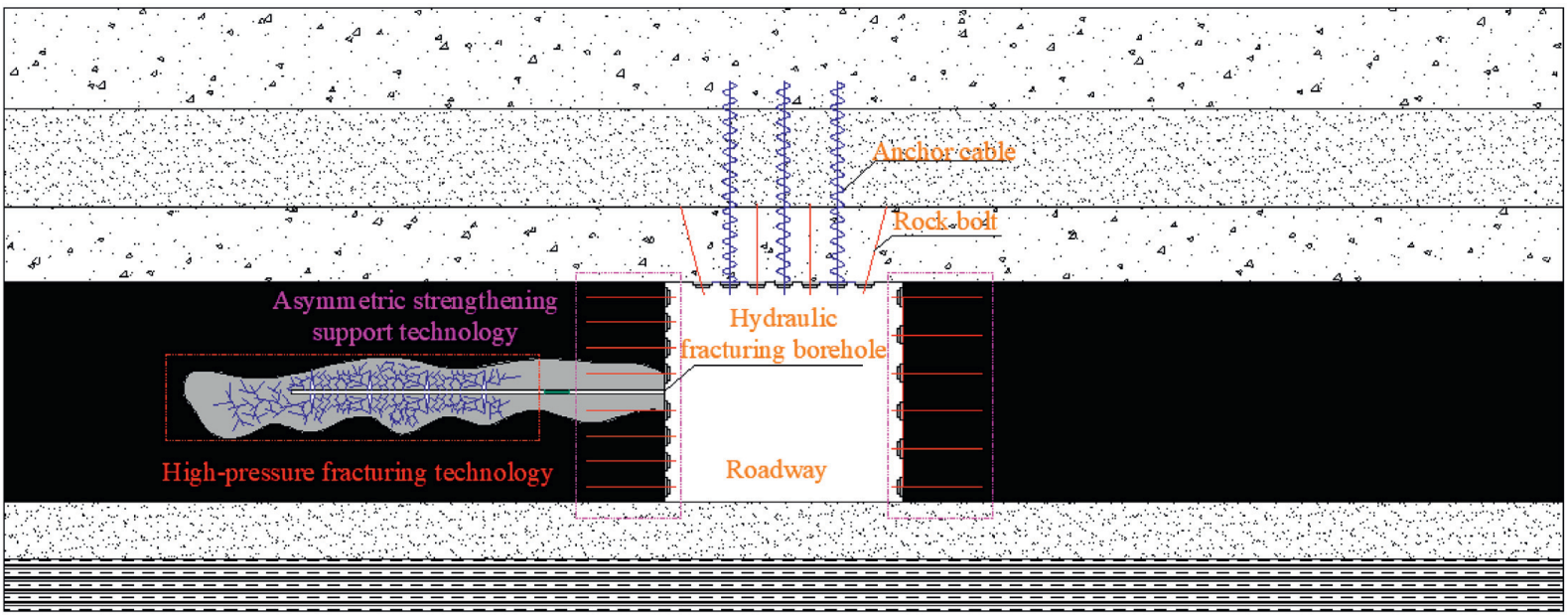

Figure 14: Control technology for surrounding rock.

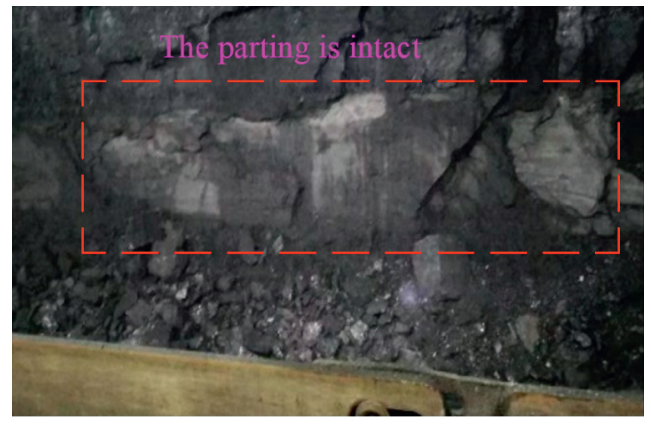

(a)

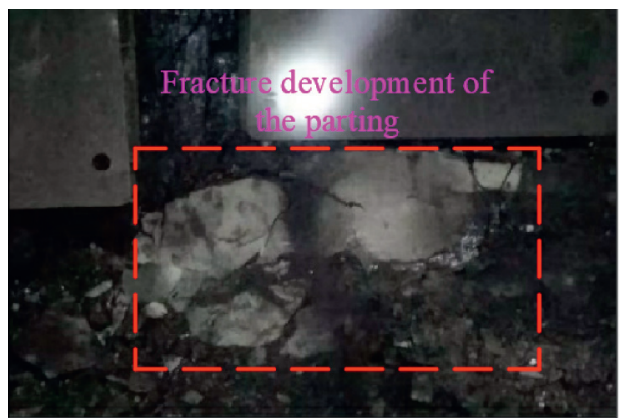

(b)

FIGURE 15: The parting before and after fracturing at the working face. (a) Before fracturing. (b) After fracturing.

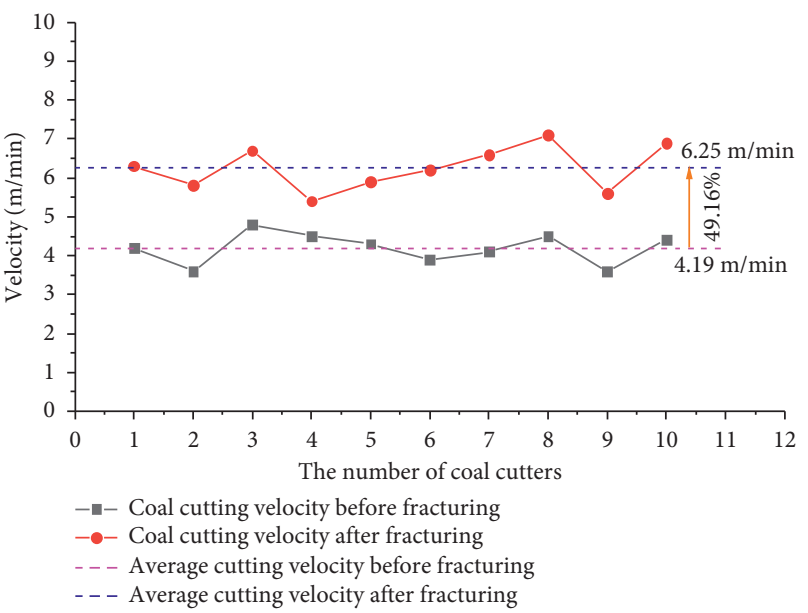

FIGURE 16: The cutting speed of the coal cutters before and after fracturing of the parting.

High-pressure pulsed prefracturing promoted crack development in the partings, reduced the parting strength, curtailed coal rib spalling and dynamic ejection of coal dust at the working face, decreased the number of cutting picks used by $36 \%$, and increased the coal cutting speed by $49.16 \%$, as shown in Figure 16. The presence of the partings resulted in a poorly formed return airway at the No. 112201 working face that exhibited significant spalling, as shown in Figure 17(a). To maintain the stability of the rocks surrounding the roadway, the support parameters were adjusted 


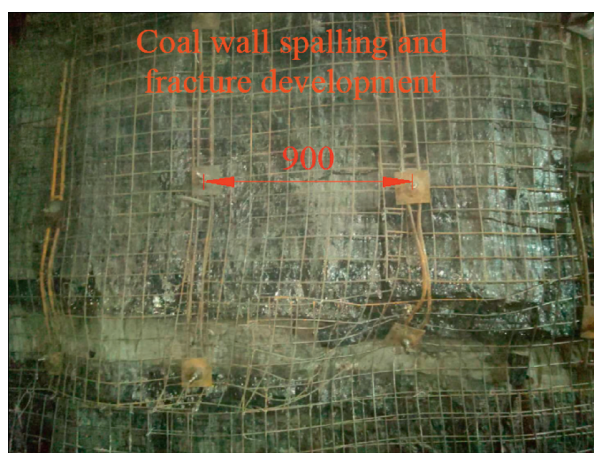

(a)

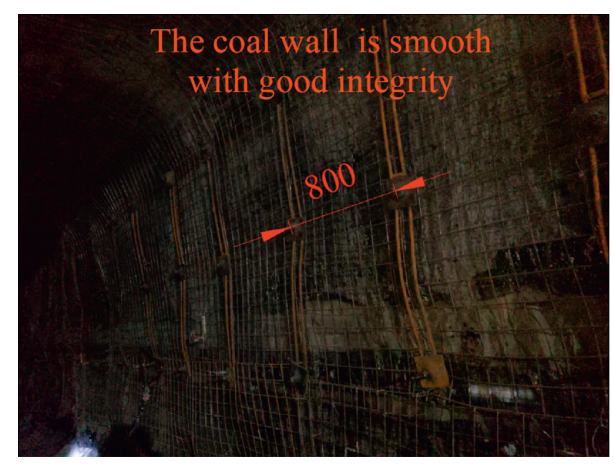

(b)

FIGURE 17: Comparison of roadway formation with different support parameters. (a) Support spacing of $900 \mathrm{~mm} \times 900 \mathrm{~mm}$. (b) Support spacing of $900 \mathrm{~mm} \times 800 \mathrm{~mm}$.

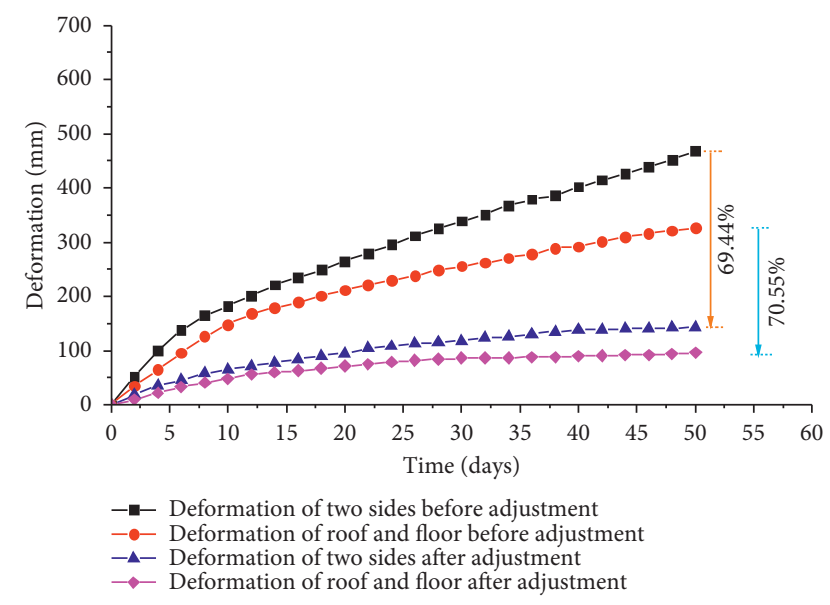

FIgURE 18: The roadway formation with different support parameters.

to increase the strength of the coal seam support system. The rock bolt spacing was changed from $900 \mathrm{~mm} \times 900 \mathrm{~mm}$ to $900 \mathrm{~mm} \times 800 \mathrm{~mm}$. Figure 17 (b) shows the performance of the roadway support system. Figure 18 shows that the adjustment notably decreased the deformation of the surrounding rocks along the two sides of the roadway and the roof and floor of the roadway by $69.44 \%$ and $70.55 \%$, respectively, while significantly increasing the stability of the rocks surrounding the roadway.

\section{Conclusions}

(1) As $\theta$ increased, the pore compaction regime of the stress-strain curve became shorter, the failure mode of the composite changed from splitting and tensile failure to slip and shear failure, the brittleness and the extent of fragmentation of the coal of the composite decreased, and its ductility increased. Additionally, as $\theta$ increased, $\sigma_{u}, E$, and $K_{e}$ of the composite decreased. Notably, the cumulative AE count curve of the composite could be divided into four characteristic regimes corresponding to the stress-strain curve: pore compaction and closure, a slowly ascending linear elastic section, prepeak steady crack propagation, and peak unsteady crack propagation.

(2) The rock parting was the key area in which elastic energy accumulated. The initiation and propagation of cracks in the coal caused the rock parting to release elastic energy, which precipitated violent failure of the composite. As $D$ increased, $\sigma_{u}, E$, and $K_{e}$ of the composite increased. In addition, as $D$ increased, the failure mode of the composite changed from ductile failure to brittle failure, and the extent of fragmentation of the coal increased.

(3) The experimental results for the coal-rock composite with a seam parting were used to formulate two technologies to control the stability of the surrounding rock, namely, high-pressure fracturing technology to weaken partings at working faces and asymmetric strengthening support technology for rocks surrounding roadways. These two technologies can effectively ensure safe and efficient production at working faces.

\section{Data Availability}

Some of the data used to support the findings of this study are included within the article, and the other supporting data are available from the corresponding author upon request.

\section{Conflicts of Interest}

The authors declare that they have no known conflicts of interest or personal relationships that could appear to influence the results reported in this paper.

\section{Acknowledgments}

The authors acknowledge the financial support provided by the National Natural Science Foundation Project of China (51564044).

\section{References}

[1] L. C. Cheng, Y. L. Qin, X. W. Li, and X. Y. Zhao, “A laboratory and numerical simulation study on compression characteristics 
of coal gangue particles with optimal size distribution based on shape statistics," Mathematical Problems in Engineering, vol. 2020, Article ID 8046156, 13 pages, 2020.

[2] M. S. Alfarzaeai, Q. Niu, J. Zhao, R. M. A. Eshaq, and E. Hu, "Coal/gangue recognition using convolutional neural networks and thermal images," IEEE Access, vol. 8, pp. 76780-76789, 2020.

[3] M. Bui, Y. Lu, W. Guo, F. Wang, and Z. Zhao, "The research on stability and supporting technology of rock in gob-side entry in thick seam with parting," Journal of Mining \& Safety Engineering, vol. 31, no. 6, pp. 950-956, 2014.

[4] R. Peng, X. R. Meng, G. M. Zhao, Y. M. Li, and J. M. Zhu, "Experimental research on the structural instability mechanism and the effect of multi-echelon support of deep roadways in a kilometre-deep well," PLoS One, vol. 13, no. 2, p. 24, 2018.

[5] H. Y. Liu, H. S. Jia, L. Fan, and B. Han, "The Theory and Practice of Forepoling Pre-stressed system bolt in preventing the rib spalling," in Resources and Sustainable Development, J. Wu, X. Lu, H. Xu, and N. Nakagoshi, Eds., Trans Tech Publications Ltd, Stafa-Zurich, Switzerland, pp. 883-887, 2013.

[6] K. Jiang, K. Gao, and L. Wan, "Effect of gangue distributions on cutting force and specific energy in coal cutting," Strojniški Vestnik-Journal of Mechanical Engineering, vol. 66, no. 3, pp. 203-212, 2020.

[7] S. F. Liu, S. F. Lu, Z. J. Wan, H. W. Zhang, and K. K. Xing, "Numerical simulation of induced cutting in deep coal," Royal Society Open Science, vol. 6, no. 9, p. 12, 2019.

[8] D. G. Li and C. S. Liu, Development and Experiment of Cutting Force Model on Conical Pick Cutting Rock at Different Wedge Angles, World Scientific Publishing Co Pte Ltd, Singapore, 2016.

[9] L. Tian, J. Mao, and Q. Wang, "Coal and rock identification method based on the force of idler shaft in shearer's ranging arm," Journal of China Coal Society, vol. 41, no. 3, pp. 782787, 2016.

[10] S. Zhu, F. Jiang, J. Liu et al., "Mechanism and monitoring and early warning technology of rock burst in the heading face of compound thick coal seam," Journal of China Coal Society, vol. 45, no. 5, pp. 1659-1670, 2020.

[11] K. Yang, Z. Wei, X. Chi, Y. Zhang, L. Dou, and W. Liu, "Experimental research on the mechanical characteristics and the failure mechanism of coal-rock composite under uniaxial load," Advances in Civil Engineering, vol. 2020, Article ID 8867809, 11 pages, 2020.

[12] F. Gao, H. Kang, and L. Yang, "Experimental and numerical investigations on the failure processes and mechanisms of composite coal-rock specimens," Scientific Reports, vol. 10, no. 1, p. 13422, 2020.

[13] Z. Qin, G. B. Chen, G. H. Zhang, Q. H. Li, and T. Li, "Tests on the dynamic failure rules of coal-rock composites," Acta Geodynamica et Geomaterialia, vol. 16, no. 1, pp. 39-54, 2019.

[14] S. Song, X. Liu, Y. Tan, D. Fan, Q. Ma, and H. Wang, "Study on failure modes and energy evolution of coal-rock combination under cyclic loading," Shock and Vibration, vol. 2020, Article ID 5731721, 16 pages, 2020.

[15] D.-X. Zhang, W.-Y. Guo, C.-W. Zang et al., "A new burst evaluation index of coal-rock combination specimen considering rebound and damage effects of rock," Geomatics, Natural Hazards and Risk, vol. 11, no. 1, pp. 984-999, 2020.

[16] P. Wang, H. Jia, and P. Zheng, "Sensitivity analysis of bursting liability for different coal-rock combinations based on their inhomogeneous characteristics," Geomatics, Natural Hazards and Risk, vol. 11, no. 1, pp. 149-159, 2020.
[17] Z. Xie, N. Zhang, F. Meng, C. Han, Y. An, and R. Zhu, "Deformation field evolution and failure mechanisms of coalrock combination based on the digital speckle correlation method," Energies, vol. 12, no. 13, p. 14, 2019.

[18] Z. Xie, N. Zhang, Y. Yuan, G. Xu, and Q. Wei, "Study on safety control of composite roof in deep roadway based on energy balance theory," Sustainability, vol. 11, no. 13, p. 18, 2019.

[19] T. Wang, Z. Ma, P. Gong, N. Li, and S. Cheng, "Analysis of failure characteristics and strength criterion of coal-rock combined body with different height ratios," Advances in Civil Engineering, vol. 2020, Article ID 8842206, 14 pages, 2020.

[20] G. B. Chen, E. Y. Wang, W. C. Wang, T. Li, and G. H. Zhang, "Experimental study on the influence of lithology and rockcoal height ratio on mechanical properties and impact effect of combined body," Energy Sources Part A-Recovery Utilization and Environmental Effects.vol. 24, 2019.

[21] S. J. Chen, D. W. Yin, N. Jiang, F. Wang, and W. J. Guo, "Simulation study on effects of loading rate on uniaxial compression failure of composite rock-coal layer," Geomechanics and Engineering, vol. 17, no. 4, pp. 333-342, 2019.

[22] Y. L. Tan, F. H. Yu, J. G. Ning, and T. B. Zhao, "Design and construction of entry retaining wall along a gob side under hard roof stratum," International Journal of Rock Mechanics and Mining Sciences, vol. 77, pp. 115-121, 2015.

[23] J. Lu, G. Huang, H. Gao, X. Li, D. Zhang, and G. Yin, "Mechanical properties of layered composite coal-rock subjected to true triaxial stress," Rock Mechanics and Rock Engineering, vol. 53, no. 9, pp. 4117-4138, 2020. 